\title{
ПСИХОЛОГИЧЕСКАЯ ГОТОВНОСТЬ СТУДЕНТОВ ПЕДАГОГИЧЕСКОГО ВУЗА К ПРОФЕССИОНАЛЬНОЙ ДЕЯТЕЛЬНОСТИ В УСЛОВИЯХ ИНКЛЮЗИВНОГО ОБРАЗОВАНИЯ
}

\begin{abstract}
В статье приводятся результаты исследования психологической готовности студентов педагогического вуза к работе с детьми с ограниченными возможностями здоровья в условиях инклюзивного образования. Рассматриваются особенности мотивационного и эмоционального компонентов в структуре психологической готовности студентов к профессиональной педагогической деятельности.

Ключевые слова: психологическая готовность к профессиональной педагогической деятельности, психолого-педагогическое сопровождение детей с ограниченными возможностями здоровья, мотивация, эмпатия.
\end{abstract}

\author{
L.S. Pilipchuk, E.V. Zhilkina
}

\section{PSYCHOLOGICAL READINESS OF PEDAGOGICAL UNIVERSITY STUDENTS FOR PROFESSIONAL ACTIVITY IN THE CONDITIONS OF INCLUSIVE EDUCATION}

\begin{abstract}
The article presents the results of a study of the psychological readiness of students of a pedagogical university to work with children with disabilities in inclusive education. The article considers the features of motivational and emotional components in the structure of psychological readiness of a person for professional pedagogical activity.

Key words: Psychological readiness for professional pedagogical activity, psychological and pedagogical support of children with disabilities, motivation of activity, empathy.
\end{abstract}

Проблема психологической готовности личности к профессиональной педагогической деятельности является одной из важнейших для современной психолого-педагогической науки. В процессе обучения в педагогическом вузе студент не только получает образование, происходит его личностное становление как специалиста: формируются новые жизненные ценности, установки, идет освоение индивидуализированных способов и приемов взаимодействия с окружающими. Эти изменения личности, результаты ее развития в период обучения в вузе являются особо важными, так как именно личность педагога и есть основной инструмент его воздействия, определяющий особенности педагогической деятельности.

Актуальной проблемой современного образования является формирование необходимого уровня психологической готовности студентов педагогического вуза к профессиональной деятельности, заключающейся еще и в психологопедагогическом сопровождении детей с ограниченными возможностями здоровья в условиях инклюзивного образования. В современных исследованиях под психолого-педагогическим сопровождением понимается гибкий, длительный и динамический процесс, предполагающий целостную, организованную и системную деятельность специалистов, направленную на создание условий для успешного функционирования всех участников единого образовательного пространства [1]. Психолого-педагогическое сопровождение является особым направлением профессиональной деятельности педагога, требующим психологической готовности к нему специалиста.

Современные исследователи предлагают разные подходы к понятию и структуре психологической готовности студентов к профессиональной деятельности. По мнению М.И. Дьяченко и Л.А. Кандыбович [2], готовность содержит в себе такие составляющие, как: мотивационная (наличие интереса к изучаемым дисциплинам); ориентационная (знание особенностей профессии); операционная (наличие знаний, умений, навыков; умение анализировать информацию); воле- 
вая (присутствие самоконтроля); оценочная (умение оценивать собственную подготовленность). А.Ю. Попова [3] выделяет три ведущие составляющие психологической готовности студентовпсихологов к предстоящей работе по профессии: мотивационная, когнитивная, личностно-смысловая. А.Ф. Бондаренко, Р. Кочюнас [4] в структуре психологической готовности в качестве ведущей выделяют личностную составляющую, к ней относят принятия себя и окружающих, эмпатию. Е.А. Климов, А.Б. Орлов $[5,6]$ также указывают на ведущую роль эмпатии в личностной готовности к профессиональной деятельности. К настоящему времени в науке сложилось определенное представление о структуре и компонентах готовности педагога к деятельности в условиях инклюзивного образования, где при всем разнообразии авторских позиций отмечается общее базовое положение - необходимость принятия личностью философии и ценностей инклюзивного подхода в образовании. Вопросы профессиональной подготовки педагогов к деятельности в условиях инклюзивного образования рассматривали С.В. Алехина, О.С. Кузьмина, В.В. Хитрюк и др. [7-10]. В структуре профессиональной готовности педагога к работе с детьми с ограниченными возможностями здоровья в условиях инклюзивной образовательной организации исследователи выделяют следующие компоненты: О.С. Кузьмина [8] считает, что готовность должна включать: понимание философии инклюзивного образования, знание психолого-педагогических закономерностей и особенностей возрастного и личностного развития детей с ОВЗ; И.В. Возняк [9] в структуре готовности педагога к работе с детьми с ОВЗ выделяет компоненты: мотивационный; когнитивный, включающий знания в области инклюзивного образования; действенный, понимаемый как совокупность умений и навыков, необходимых для реализации инклюзивного образования; рефлексивный, включающий определенные значимые для инклюзивного образования личностные качества педагога. По мнению В.В. Хитрюк [10], готовность складывается из когнитивного, эмоционального, коммуникативного, рефлексивного и конативного (наличие мотивов к самореализации в области инклюзивного образования) компонентов. Психологическая готовность педагога к профессиональной деятельности в условиях инклюзивного образования - это сложное личностное образование, длительно формируемое в результате целенаправленного обучения и творческого саморазвития, проявляющегося на личностном уровне субъективной системой, включающей в себя ценностно-мотивационный, когнитивный, операциональный и аффективный компоненты.

На наш взгляд, психологическая готовность студентов к работе в условиях инклюзивного образования представляет собой систему профессионально значимых показателей личности, включающих: социальные установки, мотивацию, эмпатию, принятие и понимание целей инклюзивного образования, знаний, которые необходимы для реализации профессиональной деятельности, осуществления психолого-педагогического сопровождения детей с ограниченными возможностями здоровья в условиях инклюзивного образования. Структура психологической готовности студентов к профессиональной деятельности в условиях инклюзивного образования представляет собой синтез компонентов, к которым относятся: мотивационный, эмоциональный и личностный. Специфика психологической готовности студентов к профессиональной деятельности может быть раскрыта через такие показатели, как социальная обусловленность учения и учебно-познавательные мотивы, просоциальные установки на альтруизм, труд, высокий уровень эмпатии и принятия ребенка с ограниченными возможностями здоровья.

Цель нашего исследования - выявить особенности психологической готовности студентов к профессиональной деятельности в условиях инклюзивного образования.

В соответствии с целью определены следующие задачи исследования:

1. Изучить характеристики психологической готовности к работе с детьми с ограниченными возможностями здоровья в условиях инклюзивного образования у студентов педагогического вуза, обучающихся по разным направлениям подготовки.

2. Определить взаимосвязь мотивационного и эмоционального компонентов психологической готовности.

Гипотеза исследования:

- компоненты психологической готовности студентов к профессиональной деятельности различаются по уровню выраженности;

- существует взаимосвязь между эмоциональным и мотивационным компонентом психологической готовности студентов к профессиональной деятельности;

- большее число студентов, готовых к реализации профессиональной деятельности в условиях инклюзии, будет наблюдаться по направлению «Специальное (дефектологическое) образование».

Были использованы следующие методики исследования: 
- «Мотивация учения студентов педагогического вуза» С.А. Пакулиной, М.В. Овчинниковой;

- тест «Методика диагностики уровней эмпатических способностей» В.В. Бойко;

- методика диагностики социально-психологических установок личности в мотивационно-потребностной сфере О.Ф. Потемкиной $[11,12]$;

- для определения уровня знаний об особенностях и специфике работы с детьми с ограниченными возможностями здоровья был использован тест контроля знаний, используемый в учебном процессе по дисциплине «Психология детей с ограниченными возможностями здоровья»;

- анкета, определяющая отношение студентов к реализации педагогической деятельности в условиях инклюзивного образования.

Данная группа методик позволяет изучить ряд показателей психологической готовности и оценить психологический потенциал студентов, спрогнозировать некоторые параметры их развития как будущих профессионалов. Исследование проводилось на базе института психологии и педагогики Алтайского государственного педагогического университета. В исследовании принимали участие студенты 3-х и 4-х курсов (91студент), которые обучаются по программам бакалавриата по направлениям: «Специальное (дефектологиче- ское) образование» (группа 1), «Педагогическое образование» (группа 2), «Психолого-педагогическое образование» (группа 3). Были получены следующие результаты: внутри групп студентов, обучающихся по разным направлениям, мы выделили респондентов с разными уровнями сформированности психологической готовности. В группе студентов, обучающихся по направлению «Специальное (дефектологическое) образование», мы получили следующие результаты: 16 \% респондентов имеют высокий уровень сформированности психологической готовности, $65 \%$ респондентов - средний уровень сформированности психологической готовности, $19 \%$ респондентов - низкий уровень сформированности психологической готовности. В группе студентов, обучающиеся по направлению «Педагогическое образование»: 10 \% респондентов с высоким уровнем сформированности психологической готовности, $77 \%$ - со средним уровнем и $13 \%$ - с низким уровнем психологической готовности. В группе студентов, обучающихся по направлению «Психолого-педагогическое образование»: 16 \% респондентов с высоким уровнем психологической готовности, $77 \%$ - со средним уровнем и 7 \% - низким уровнем сформированности психологической готовности (см. рис. 1).

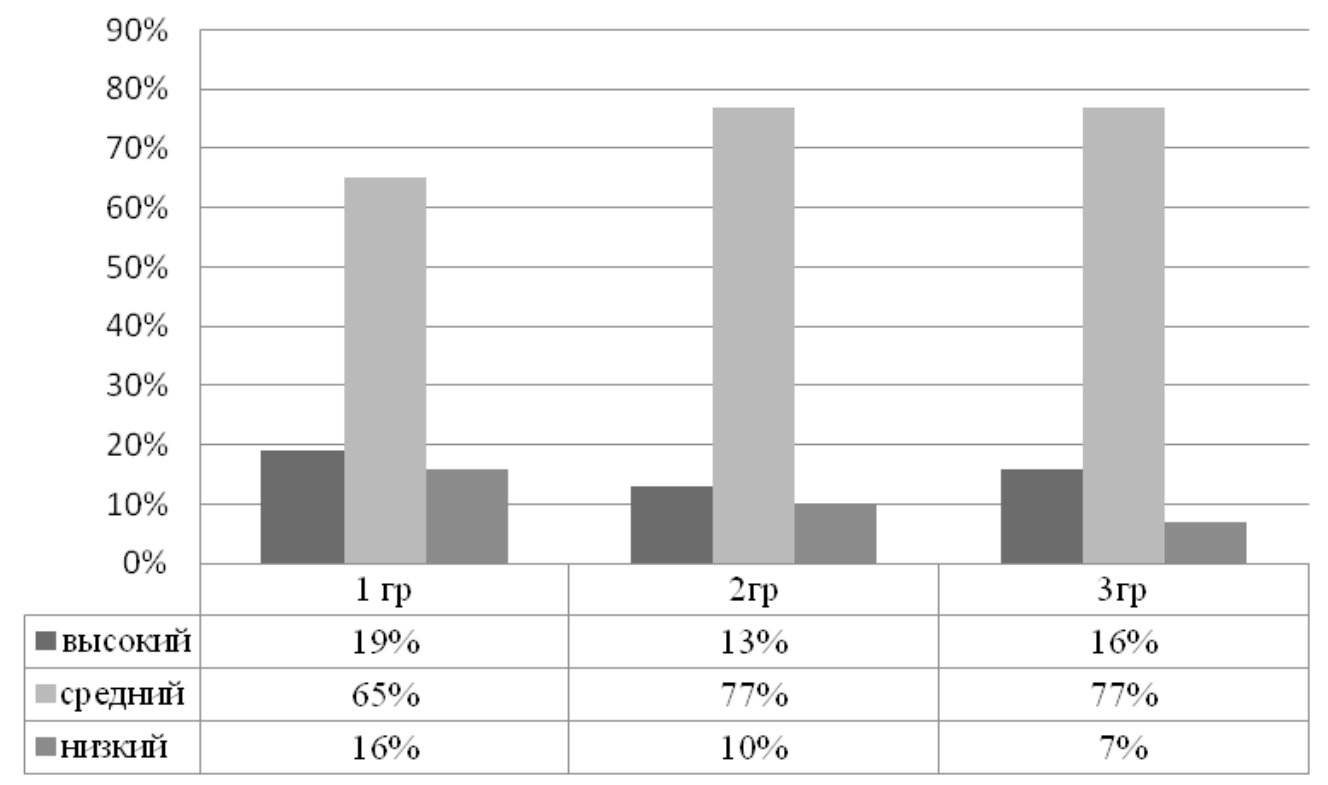

Рис. 1. Распределение по уровням сформированности психологической готовности студентов, обучающихся по разным направлениям

Согласно представленным данным, значимых отличий между студентами разных направлений по уровням сформированности психологической готовности не выявлено.
Исследование структурных компонентов психологической готовности по предлагаемым методикам позволяет выделить уровни сформированности психологической готовности, высо- 
кий уровень психологической готовности - это высокий уровень развития эмпатии, внутренняя мотивация учения, преобладание просоциальных установок на альтруизм и труд. Низкий уровень сформированности психологической готовности предполагает: безразличие, холодность, эмоциональную неустойчивость, пренебрежение с преобладанием в учебной деятельности внешней мотивации, степень выраженности социальнопсихологических установок проявлена слабо, отсутствуют просоциальные установки.

В соответствии с полученными данными, мы можем кратко охарактеризовать особенности психологической готовности студентов разных направлений обучения. У студентов, обучающихся по направлению «Педагогическое образование», преобладает средний уровень развития эмпатии, что выражается в готовности в нужный момент проявить сочувствие к человеку, но при этом нет стремления всецело проникнуться состоянием партнера. Эмпатические способности не развиты в полной мере, особенно это касается рационального канала эмпатии и интуитивных способностей в эмпатии, что проявляется в безразличии, эмоциональной неустойчивости и пренебрежении к людям. Согласно результатам, студенты данного направления обучения показывают средний уровень осведомленности о психологии и методах работы с детьми с ограниченными возможностями здоровья. Ярко выражены следующие социально-психологические установки, актуальные для данной группы студентов: установки на процесс, альтруизм и свободу. Эти социально-психологические установки характеризуют студентов следующим образом: они меньше задумываются над достижением результата, часто опаздывают со сдачей работы, их процессуальная направленность препятствует зачастую их результативности; ориентируются на альтруистические ценности, часто в ущерб себе, и ориентированы на свободу. В данной группе студентов преобладает внешняя мотивация учения (узкопрофессиональные мотивы в учебной деятельности и мотивах профессиональной деятельности), при преобладании внутренних мотивов поступления в вуз. Неустойчивая профессиональная мотивация, сочетающая в себе безвыходность в профессиональном выборе, формально-приспособительное учение сочетаются с достаточно высоким уровнем мотивации поступления в вуз. Таким образом, можно отметить, что во время обучения у студентов направления «Педагогическое образование» социальная значимость педагогической профессии снижается.
Студентов, обучающихся по направлению «Специальное (дефектологическое) образование» с точки зрения психологической готовности можно охарактеризовать следующим образом. Средний уровень развития эмпатии при низком уровне развития рационального канала эмпатии, проявляется в невнимании, холодности и безразличии, в отсутствии цепкости восприятия за реакциями и состояниями другого человека. Социально-психологические установки сглажены и ярко не выражены, характеризуются направленностью на труд и свободу. Можно отметить, что ориентации на власть и деньги выражены слабо, в целом невысокие и средние показатели по всем социально-психологическим установкам говорят о невысоком уровне мотивации. У данной группы студентов можно отметить неустойчивость мотивации, сочетающую в себе безвыходность в профессиональном выборе, формально-приспособительное учение, ориентацию на результат при преобладании внутренней мотивации поступления в вуз. Также преобладают внешние мотивы, не связанные с самим процессом учения (не отставать от сокурсников, достичь уважения преподавателей, избежать осуждения и наказания).

Для студентов направления «Психолого-педагогическое образование» характерны те же особенности психологической готовности, а именно средний уровень эмпатии при низких показателях интуитивных способностей в эмпатии, которые проявляются в избегании личных контактов. Студенты с низким уровнем интуитивных эмпатических способностей считают неуместным проявлять любопытство к другой личности, спокойно относятся к переживаниям и проблемам окружающих.

Социально-психологические ориентации выражены в средней степени, что говорит о невысокой мотивации и гармоничной ориентации. Наиболее выраженной установкой для студентов этой группы является ориентация на свободу, при средних невыраженных показателях просоциальных установок на альтруизм и труд. В учебной деятельности преобладает внешняя мотивация, которая характеризуется узкими познавательными мотивами и иррелевантными профессиональными мотивами. Внешние мотивы составляют мотивацию заданного и стихийного учения, основанную на действиях, которые студенту задали выполнить, а результатом являются исполнительские действия. При поступлении в вуз студенты этой группы так же руководствовались внутренними мотивами. 
Достоверные различия между группами студентов, обучающихся по разным направлениям, выявлены согласно t-критерию Стьюдента по следующим показателям: проявление эмпатии (рациональный канал эмпатии, установки в эмпатии) и уровень осведомленности о психологии детей с ОВ3.

Рациональный канал эмпатии, характеризующий направленность внимания, восприятия и мышления эмпатирующего на сущность любого другого человека, на его состояние, поведение, проявляющийся в спонтанном интересе, наиболее свойственен студентам педагогам-психологам. У студентов данной группы он развит на среднем и высоком уровне по отношению к другим группам, тогда как у студентов направлений «Педагогическое образование» ( «Специальное (дефектологическое) образование» ( низкий уровень развития рационального канала эмпатии. При низких значениях рационального канала эмпатии эмоциональные проявления у студентов находятся под контролем. Это выражается в готовности в нужный момент проявить сочувствие к человеку, который в этом нуждается, но при этом нет стремления проникнуться состоянием партнера. Возможно избегание личных контактов, отсутствие любопытства к другой личности, спокойное отношение к переживаниям и проблемам окружающих вплоть до безразличия, холодности и пренебрежения. Также у студентов педагогов-психологов наиболее выражены установки, способствующие эмпатии, тогда как у двух других групп установки в эмпатии сглажены и ярко не выражены. Студенты группы «Специальное (дефектологическое) образование» показали высокий уровень знаний о психологии детей с ограниченными возможностями здоровья, по отношению к группе 2 ( кие баллы по тесту проверки знаний у студентов направления «Психолого-педагогическое образование» свидетельствуют о плохой ориентации в психологии детей с ограниченными возможностями здоровья ( с группой студентов, обучающихся по специальности «Специальное (дефектологическое) образование»).

По остальным показателям нашего исследования статистически значимых различий не обнаружено. Таким образом, можно отметить, что существуют значительные различия в выраженности структурных компонентов психологической готовности к профессиональной деятельности в условиях инклюзивного образования у студентов разных направлений обучения, это обусловлено не только уровнем их знаний о психологии детей с ограниченными возможностями здоровья, но и уровнем эмпатии.

Результаты анкетирования всей выборки студентов показали, что респонденты отмечают значимость и принимают цель инклюзивного образования (которую видят в социализации детей с особыми образовательными способностями), но считают себя не готовыми к реализации профессиональной деятельности в условиях инклюзии ( $82 \%$ респондентов от общей выборки). При этом указывают следующие причины: «...не хватает знаний о методах, технологиях работы с детьми» (48 \% респондентов), «...сложности будут в ходе решения задач педагогической практики и осуществления взаимодействия со специалистами и родителями в педагогическом процессе...» (61 \%), «...нет четких представлений о реализации психолого-педагогического сопровождения детей с разными видами нарушений развития» (74 \%). Исключение составляет выборка студентов, обучающихся по направлению «Специальное (дефектологическое) образование», которые считают, что они успешно смогут решить практические вопросы, связанные с обучением и развитием детей с особыми образовательными потребностями в инклюзивной образовательной организации.

Для исследования связей внутри изучаемых компонентов психологической готовности мы использовали корреляционный анализ. Анализ и интерпретация результатов, полученных при применении корреляционного анализа, строились на выявлении значимых связей, как между компонентами структуры психологической готовности, так и внутри самих компонентов.

Мотивационный компонент. У студентов с выраженными ориентациями на результат, труд и власть преобладает внутренняя мотивация учения. Внутренние мотивы поступления обусловлены ориентацией на альтруизм и труд. Больше всего корреляционных связей с внутренней и внешней мотивацией обнаружено с социальнопсихологической установкой на труд. Что может свидетельствовать о том, что при внешней мотивации ориентация на труд обусловлена присутствием внешнего подкрепления или зависимости от других факторов, при внутренней мотивации ориентация на труд связана с интересом к профессии, желанием приобретать глубокие знания и получать интеллектуальное удовлетворение от учебной деятельности. Внешние мотивы профессиональной деятельности связаны с ориентаци- 
ей на эгоизм и власть, при доминировании этих ориентаций ведущей ценностью респондентов является влияние на других и на общество. Так же внешние мотивы профессиональной деятельности связаны с ориентацией на результат, т. е. в своей деятельности студенты действуют вопреки суете, помехам и неудачам, при этом в стремлении к достижению результата могут забыть обо всем остальном. Таким образом, мы видим, что такие просоциальные установки, как альтруизм и труд, связаны с внутренней мотивацией студентов (см. табл. 1), но ориентация на труд связана и с внешними учебными и профессиональными мотивами (получить высокооплачиваемую работу, не отставать от сокурсников, выполнять педагогические требования).

Таблица 1

Корреляционные взаимосвязи переменных мотивационного компонента психологической готовности (данные по всей выборке респондентов)

\begin{tabular}{|c|c|c|c|c|c|c|c|c|}
\hline \multirow[b]{2}{*}{$\begin{array}{c}\text { Мотивация } \\
\text { учения }\end{array}$} & \multicolumn{8}{|c|}{ Социально-психологические установки } \\
\hline & 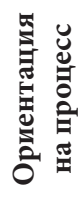 & 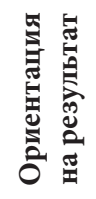 & 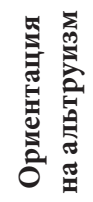 & 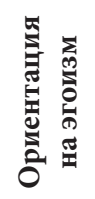 & 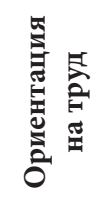 & 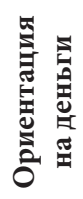 & 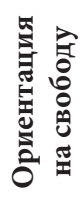 & 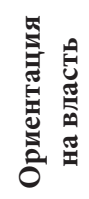 \\
\hline Внутренняя мотивация & &, $302^{*}$ & & &, $412^{\star *}$ & & &, $343^{* *}$ \\
\hline $\begin{array}{l}\text { Внутренние мотивы } \\
\text { поступления в вуз }\end{array}$ & & &, $322^{*}$ & & $420^{* *}$ & & & \\
\hline $\begin{array}{l}\text { Внутренние реально } \\
\text { действующие мотивы }\end{array}$ & & & & &, $290^{*}$ & & & \\
\hline $\begin{array}{c}\text { Внутренние мотивы } \\
\text { профессиональной } \\
\text { деятельности }\end{array}$ & &, $343^{\star *}$ & & & & & &, $380^{\star *}$ \\
\hline Внешняя мотивация & &, $314^{*}$ & & &, $387^{\star *}$ & & & \\
\hline $\begin{array}{c}\text { Внешние мотивы } \\
\text { поступления в вуз }\end{array}$ & & & & ,304* & & & & \\
\hline $\begin{array}{c}\text { Внешние реально } \\
\text { действующие мотивы }\end{array}$ & & & & &, $390^{* *}$ & & & \\
\hline $\begin{array}{c}\text { Внешние мотивы } \\
\text { профессиональной деятельности }\end{array}$ & & $329^{* *}$ & &, $254^{*}$ &, $259^{*}$ & & & $263^{*}$ \\
\hline
\end{tabular}

Примечание: ${ }^{* *}-p \leq 0,05,{ }^{*}-p \leq 0,01$

В ходе исследования структуры эмоционального компонента и его связей с мотивационным компонентом мы получили следующие результаты (см. табл. 2). Способность к эмпатии, которая расценивается как важное коммуникативное свойство человека, позволяющее создавать атмосферу открытости, доверительности, задушевности, отрицательно коррелирует с ориентацией на эгоизм и деньги. Таким образом, эти установки препятствуют проникающей способности в эмпатии, соответственно, чем выше у респондента показатель проникающей способности в эмпатии, тем меньшую ценность представляют деньги, а ориентация на эгоизм переходит в альтруистиче- ские наклонности. Высокий уровень эмпатии, а именно развитость эмоционального канала эмпатии и проникающей способности, коррелирует с просоциальной установкой на труд и альтруизм. Способность к сопереживанию, эмоциональная отзывчивость, умение понять другого на основе постановки себя на место партнера, легкость, подвижность и гибкость эмоций подразумевают альтруистическую направленность эмпатии. Эгоизм и альтруизм в характере и поведении отдельного человека выступают как противоположные качества единого психогенетического свойства, соответственно, ориентация на эгоизм подразумевает низкий уровень развития эмпатических 
способностей. Необходимым условием для проявления любых реакций по отношению к другому человеку является способность воспринимать другого человека, т. е. иметь чувствительность к человеку вообще. Основная реакция альтруизма сострадание - требует умения понимать чужое страдание и давать ответ, нацеленный на его облегчение. Социально-психологическая установка на результат выражается в стремлении достичь результата в своей деятельности вопреки всему (суете, помехам, неудачам), коррелирует с такой эмпатической способностью как идентификация. Ярко выраженная направленность на результат способствует развитию таких качеств эмпатии, как умение понять другого на основе сопереживания и постановки себя на место партнера.

Таблица 2

Корреляционные взаимосвязи переменных мотивационного и эмоционального компонентов психологической готовности (данные по всей выборке респондентов)

\begin{tabular}{|c|c|c|c|c|c|c|c|c|c|}
\hline \multirow[b]{2}{*}{$\begin{array}{l}\text { Эмпатические } \\
\text { способности }\end{array}$} & \multicolumn{9}{|c|}{ Мотивы учения. Социально-психологические установки } \\
\hline & 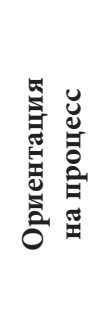 & 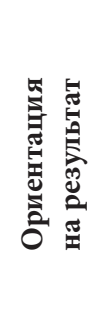 & 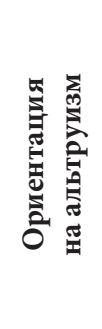 & 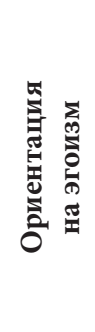 & 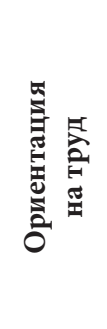 & 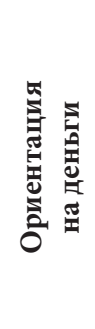 & 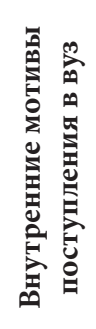 & 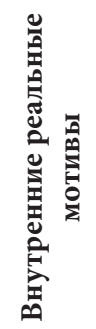 & 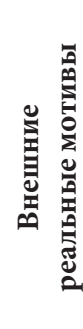 \\
\hline $\begin{array}{c}\text { Эмоциональная } \\
\text { эмпатия }\end{array}$ &, $380^{* *}$ & &, $539^{* *}$ & &, $355^{\star *}$ & &, $288^{*}$ &, $328^{* *}$ & $429^{* *}$ \\
\hline Рациональный канал & $406^{* *}$ & & & & & & & & \\
\hline Эмоциональный канал & & &, $347^{\star *}$ & & $289^{*}$ & & $252^{*}$ & $428^{\star *}$ &, $550^{* *}$ \\
\hline \multicolumn{10}{|l|}{ Интуитивный канал } \\
\hline Установки & & & & & & & &, $293^{*}$ &, $441^{* *}$ \\
\hline $\begin{array}{c}\text { Проникающая } \\
\text { способность }\end{array}$ & & &, $267^{*}$ &,$- 300^{*}$ & &,$- 294^{*}$ & & & \\
\hline Идентификация & &, $480^{\star *}$ & & & & &, $337^{\star *}$ & & $379^{* *}$ \\
\hline
\end{tabular}

Высокий уровень связи выявлен между эмпатическими способностями, такими как установки и идентификация, эмоциональный канал эмпатии, и внешними реально действующими мотивами. Внешние учебные мотивы, которые можно охарактеризовать как мотивы учебного благополучия, и позиционные социальные мотивы, выражающиеся в учебной деятельности внешними побуждениями, такими как не отставать от сокурсников, заслужить уважение преподавателей и в целом одобрение окружающих, активизируют способность студентов к эмпатии. Высокий уровень развития эмпатических способностей коррелирует с внутренней мотивацией поступления в вуз. Широкие учебно-познавательные мотивы связаны с установками в эмпатии и эмоциональным каналом развития эмпатии. Способность к сопереживанию и соучастию, эмоциональная отзывчивость, а также способность действовать в условиях дефицита исходной информации напрямую связаны с высокой когнитивной гибкостью в учебной деятельности и творческим решением проблем, а также с непосредственным интересом к самим приобретаемым профессиональным знаниям, умениям и навыкам.

Полученные результаты свидетельствуют о статистически значимой корреляции между различными составляющими эмоционального и мотивационного компонентов психологической готовности: собственно эмпатией (эмпатическими способностями), социально-психологическими установками (установки на альтруизм и труд) и мотивацией учебной деятельности (внутренние 
мотивы поступления в вуз, широкие учебно-познавательные мотивы и мотивы профессиональной деятельности). Рассматривая психологическую готовность к профессиональной деятельности как совокупность мотивационных, личностных, эмоциональных характеристик субъекта, по результатам исследования мы отмечаем: у студентов недостаточно сформирована психологическая готовность к работе в условиях инклюзивного образования, что проявляется в низкой мотивации и недостаточном уровне знаний о технологиях работы с детьми с особыми образовательными потребностями, а также несформированном представлении о функционале и взаимодействии специалистов в ходе психолого-педагогического сопровождения, поверхностном понимании ценностей инклюзивного образования, недостаточной выраженности эмпатии и просоциальных установок, необходимых для реализации педагогической деятельности в инклюзивном образовании, что подтверждает допущения выдвинутой гипотезы.
Повышение уровня психологической готовности возможно через решение следующих задач: формирование мотивационной готовности студентов к работе с детьми с ограниченными возможностями здоровья в условиях инклюзивного образования (мотивационный компонент); формирование эмпатийного отношения к таким детям (эмоциональный компонент); формирование и развитие системы профессионально значимых качеств личности (открытость, эмоциональная стабильность, сознательность, самостоятельность - личностный компонент). Таким образом, подготовка будущих педагогических кадров для работы в условиях инклюзивного образования должна быть направлена на получение сведений об особенностях детей с ограниченными возможностями здоровья, на профессионально-личностное развитие студента, формирование ценностной позиции будущего педагога как необходимых показателей психологической готовности к деятельности.

\section{Библиографический список}

1. Алехина С. В. Подготовка педагогических кадров для инклюзивного образования // Педагогический журнал Башкортостана. 2013. № 1 (44). С. 26-32.

2. Дьяченко М. И., Кандыбович Л. А. Психологические проблемы готовности к деятельности. Минск: Изд-во БГУ, 1976. 175 с

3. Попова А. Ю. Психологические условия профессионального становления студентов-психологов // Психология в высшей школе: проблемы и перспективы развития: материалы III научно-практической конференции. Рязань, 2003. С. 67-69.

4. Бондаренко А. Ф. Психологическая помощь: теория и практика. Изд. 3-е, испр. и доп. М.: Независимая фирма «Класс», 2001. 336 с.

5. Климов Е. А. Психология профессионального самоопределения. М.: Академия, 2004. 304 с.

6. Орлов А. Б., Орлова Н. А. Индивидуальность и индивидность: роковой вопрос современности // Мир психологии. 2011. № 1. С. 32-44.

7. Алехина Н. В., Алексеева М. Н., Агафонова Е. Л. Готовность педагогов как основной фактор успешности инклюзивного процесса в образовании // Психологическая наука и образование. 2011. № 1. С. 83-92.

8. Кузьмина О. С. Особенности организации подготовки педагогов к работе в условиях инклюзивного образования // Инклюзивное (интегрированное) образование: от теории к практике: сборник материалов научнопрактической конференции с международным участием. Омск, 2013. С. 39-48.

9. Возняк И. В., Коваленко В. И. Развитие операционально-деятельностного компонента готовности педагогов к инклюзивному образованию детей с ограниченными возможностями здоровья // Образование и общество. 2015. № 3 (92). С. 64-67.

10. Хитрюк В. В. Инклюзивная готовность педагогов: педагогическая система формирования. Барановичи: БарГУ, 2015. 176 с.

11. Райгородский Д. Я. Практическая психодиагностика: методики и тесты. М.: Бахрах-М, 2011. 672 с.

12. Елисеев О. П. Практикум по психологии личности. СПб.: Питер, 2001. 560 с. 